\title{
A controvérsia em torno da internação involuntária de usuários de crack
}

\author{
Ygor Diego Delgado Alves* \\ \& Pedro Paulo Gomes Pereira**
}

Resumo: O objetivo deste artigo é mapear a controvérsia em torno da internação involuntária de usuários de drogas, particularmente do crack, no Brasil. Para tal, apoiamo-nos em notícias fornecidas pela mídia, na legislação e nos regulamentos e normas editadas por órgãos públicos no período de 1998 a 2012. Isso nos proporcionou uma visão geral das vozes presentes no debate público que evidenciavam, através de seus diversos atores, o processo de funcionamento da controvérsia, a crise a ser debelada e as situações consideradas de risco. Afloram dessa controvérsia um Programa e um Antiprograma, que são, respectivamente, a internação maciça de usuários de crack ou, seu oposto, as medidas de redução de danos que reservam à internação um papel muito restrito. Concluímos que a ideia disseminada da epidemia do consumo de crack ensejou no país a consciência de estarmos todos em risco; e uma prática política de governar fora das regras.

Palavras-chave: Controvérsia. Crack. Drogas. Internação. Latour.

\section{Controversy surrounding the involuntary commitment of crack cocaine users}

Abstract: This article's objective is to map the controversy surrounding the involuntary commitment of drug users in Brazil, especially among crack cocaine users. The research is based on media reports, legislation, and on the regulation and norms created by public agencies between 1998 and 2012. Because of its scope, the research presents a general vision of the diverse actors participating in public debate regarding drug use and commitment, in addition to the processes through which this controversy takes hold, the crisis that these processes aim to suppress, and the situations that considered to present considerable risk. As a result of this controversy, both a Program and an Anti-Program have taken root: respectively, these refer to the large-scale commitment of crack users; or, on the contrary, harm-reduction measures that limit commitment to a significantly reduced role. We conclude that the widespread idea of the crack cocaine epidemic has made the country aware that we are all at risk; and political practice of ruling out of the rules.

Keywords: Controversy. Crack. Drugs. Commitment. Latour.

\footnotetext{
* Ygor Diego Delgado Alves é antropólogo, graduado e mestre em ciências sociais pela Pontifícia Universidade Católica de São Paulo, doutor em antropologia pela Universidade Federal da Bahia. Atualmente, é pós-doutorando em saúde coletiva pela Universidade Federal de São Paulo (Unifesp), São Paulo, São Paulo, Brasil. Orcid: 00000002-6730-3255. <antropologiaygor@ yahoo.com.br>.

** Pedro Paulo Gomes Pereira é mestre (1996) e doutor (2001) em antropologia pela Universidade de Brasília (UnB), pós-doutoramento na Universidade de Barcelona (2001-2002). É livre docente pela Universidade Federal de São Paulo (2013), professor associado da Universidade Federal de São Paulo (Unifesp), São Paulo, São Paulo, Brasil. Orcid: 00000002-0298-2138. $<$ pedropaulopereira @hotmail.com>.
} 


\section{Introdução}

E

ste artigo analisa a controvérsia em torno da internação involuntária de usuários de drogas, particularmente do crack, no Brasil, entre os anos de 1998 a 2012, no intuito de perceber como pessoas e instituições são afetadas ao serem colocadas em movimento por drogas, controvérsias, terapêuticas e políticas públicas.

Propostas de internação em massa - que aqui denominamos Programa - acabam se contrapondo a políticas de redução de danos - ou Antiprograma. Na controvérsia que se instala, é atualizada a legislação sobre drogas de 1934, que previa internamento dos usuários que colocassem a vida em risco. A visão de que usar crack se compara ao suicídio é reiterada em campanhas midiáticas. O consumo do crack nas ruas passa a ser visto por certa literatura médica como situação de crise e de ameaça ao direito à vida, o que acaba por justificar atividades correspondentes de manejo dessa situação como a revogação da liberdade e a internação forçada.

Por quatro anos, fizemos a etnografia da cena de uso de crack em São Paulo. Neste período, acompanhamos de perto a controvérsia sobre a internação compulsória. Inspirados em Latour (2012), estabelecemos uma linha do tempo e passamos a fazer um mapa espaço-temporal dessa controvérsia. Para este autor, controvérsias são questões que ainda não produziram consenso, sobre as quais os atores discordam ou concordam em discordar. Quando as questões se estabilizam em caixas pretas, as controvérsias apagam-se até que um novo conflito apareça (Latour, 2012; Venturini, 2010). Latour (2012) nos convida a mapear as controvérsias, registrando as perspectivas dos atores, suas interações e as formas de conexão. O procedimento visa criar um mapa com informações dos diferentes atores sobre a controvérsia em questão. Registramos as manifestações destes atores sobre o tema, por um período de quatro anos. Tal procedimento permitiu-nos visualizar os momentos em que a controvérsia se tornava mais aguda ou se arrefecia; permitiu mapear os atores envolvidos (pessoas, entidades, órgãos públicos, documentos). Buscamos, portanto, realizar pesquisa documental, pesquisa de dados de bases públicas e da produção das ciências sociais sobre o tema, além do acompanhamento de postagens em sites e nas redes sociais.

A pesquisa acadêmica em torno das controvérsias a respeito da internação estritamente involuntária ainda é exígua e costuma girar em torno de aspectos jurídicos como a pertinência do habeas corpus (Pinheiro, 2013). Análises sobre controvérsias em torno da internação compulsória, motivada por decisão judicial e não apenas médica, que, por vezes, também tratam da modalidade involuntária, são mais nu- 
merosas e cobrem um espectro maior de temas, embora exames de questões jurídicas também se façam presentes (De Aguiar Pinheiro, 2013; De França, 2012; Monteiro, 2015). Ruiz e Marques (2015) também trataram da legislação sobre drogas, mas, vão além, abordam a responsabilidade e a capacidade de decisão do usuário e os meios mais adequados de tratamento e reinserção. Kerr Pontes, Santos Meza e Gastalho De Bicalho (2015) analisaram três controvérsias a respeito da internação compulsória:
i. a epidemia do crack;
ii. a capacidade de autodeterminação dos usuários; e,
iii. a limpeza social como tática de invisibilizar.

Haveria por trás de leis, pretensamente dedicadas à defesa da saúde pública, uma intenção higienista, amparada na guerra às drogas, em que discursos sobre o risco acabam por engendrar políticas de controle e vigilância. Outro trabalho que também se baseou nas ideias sobre rede sociotécnica de Bruno Latour, só que, desta vez, voltado aos discursos médicos, foi o desenvolvido por Maurício Fiore (2007). O autor tratou das controvérsias em torno da conceituação do que seriam as drogas; de seu consumo como sendo ou não uma patologia; e, ainda, das possíveis classificações das substâncias e dos tipos de uso que as pessoas possam fazer delas. A ideia de controle de riscos também é acionada, na medida em que pode servir de chave para se compreender certas ofensivas sobre as liberdades individuais, como são as internações.

Para contribuir com os trabalhos até agora produzidos sobre o tema, procuramos delimitar Programa e Antiprograma conflitantes, buscando com uma multiplicidade de atores que extrapolaram o campo jurídico e médico. Esta cobertura alargada da controvérsia permitiu vislumbrar um campo complexo de interesses e posicionamentos.

\section{A legislação que rege a internação involuntária de usuários de crack}

No tocante à legislação atual - Lei n.o 10.216, de 6 de abril de 2001 -, nada existe sobre os critérios para direcionar o julgamento do profissional médico na internação involuntária (Dalsenter \& Timi, 2012; Novaes, 2014). A intenção da lei era a de contrapor-se frontalmente ao seu antecessor normativo, o Decreto n. 0 25.559, de 3 de julho de 1934, que, segundo alguns, "convalidava o estatuto de incapacidade civil genérico de todos os pacientes" (Delgado, 2011: 117). Porém, a legislação var- 
guista da década de 1930 ainda aparece como a grande referência, pelo menos no que se refere ao discurso sobre as justificativas para a internação involuntária. Ao contrário da omissa legislação atual, a lei de 1934 trata das condições propícias à internação. De acordo com o artigo 7o, parágrafo 1ํ, em seu item "c", estão sujeitos à internação

os indivíduos suspeitos de doença mental que ameaçarem a própria vida ou a de outrem, perturbarem a ordem ou ofenderem a moral pública e não protestarem contra sua hospitalização (Brasil, 1934: 3).

Essa conceituação ainda aparece no debate atual sobre drogas e saúde, sendo mesmo repetida em materiais contrários à internação compulsória. Em folder do Conselho Regional de Psicologia de São Paulo (CRPSP), ela ressurge em tom de justificativa:

A internação compulsória [...] indicada apenas quando a pessoa está pondo em risco sua própria vida ou a de terceiros [...] (CRPSP, 2013: 3).

Para justificar essa sua posição, faz menção à Lei n.o 10.216, de 6 de abril de 2001, que nada diz sobre as condições em que a internação é possível. O CRPSP é contrário à internação involuntária de usuários de crack, avaliada como medida de exclusão e higiene social (Coelho \& Oliveira, 2014), porém, na base de seus argumentos estão princípios análogos aos dos defensores do encarceramento psiquiátrico. $\mathrm{O}$ deputado Fernando Capez (PSDB/SP), em artigo publicado em veículo midiático de grande circulação, afirmou:

A internação involuntária do dependente que perdeu sua capacidade de autodeterminação está autorizada pelo artigo 6ㅇ, inciso II, da Lei n.o 10.216/2001 (Capez, 2011).

Para esse parlamentar, no referido artigo, o direito de ir e vir não pode prevalecer sobre o direito à vida, que tem sido colocada em risco quando o usuário de crack passa a frequentar os perigosos ambientes de uso da droga. Isso tornaria possível e mesmo necessária - a internação forçada. O uso do crack, sob algumas condições, passa a ser considerado um atentado contra a própria vida, ou seja, algo semelhante à tentativa de suicídio.

A legislação de que se valeu Capez (2011), em sua defesa sobre a internação de usuários de crack, é fruto do movimento pela reforma psiquiátrica brasileira que tem sua origem em meados dos anos 1970, em busca de um novo modelo de tratamento substitutivo dos manicômios (Pitta, 2011). Esse movimento havia incluído as clínicas 
e as comunidades terapêuticas no mesmo rol das instituições manicomiais que deveriam ser substituídas por serviços públicos e ações intersetoriais que buscassem ocupar "o lugar das drogas nos projetos de vida dos usuários" (Pitta, 2011: 4588).

Com o novo quadro legal proporcionado pela Lei $n$. o 10.216/2001, aspectos da antiga legislação de 1934 - que possibilitava a existência de manicômios no país passam a ser mobilizados por aqueles que desejam realizar internações em comunidades terapêuticas. Como é o caso da ameaça à integridade física do paciente e de familiares, à moral e à ordem pública e do estado de abandono, que pode ser comparado à situação de rua. Em certos aspectos, a prática atual é menos cuidadosa que a anterior. Por exemplo, uma internação involuntária necessita de requisição médica. Antes, o médico autor do requerimento para a internação não poderia ser também o responsável pelo ingresso na instituição de internação.

A internação involuntária praticada atualmente se vale de certos aspectos presentes na legislação de 1934, mas, dispensa outros, encontrando-se, de certa forma, muito aquém da Lei n.o 24.559. Não fosse o artigo 14 desta lei declarar, em prejuízo da vontade do paciente, ser possível após "simples atestação médica" recolher em estabelecimento psiquiátrico os "casos urgentes" e também "em benefício do paciente ou como medida de segurança pública" (Brasil, 1934), o usuário de drogas ficaria atualmente em situação muito menos segura se comparada com a vigente na primeira metade do século passado. Percebemos que, nos discursos das clínicas e dos especialistas do programa em que se baseia a internação maciça, os casos urgentes constantes na antiga legislação são aqueles que, na atualidade, estão designados como casos de risco, como pessoas em situação de rua, como portadores de conduta pouco condizente com o almejado pelo convívio familiar, como aqueles que apresentam mudanças indesejadas no comportamento e os que andam em más companhias, com outros usuários ou traficantes. Da mesma forma, fica a critério da família designar os limites daquilo que é considerado capaz de colocar a pessoa em risco.

\section{A internação involuntária na mídia}

As campanhas publicitárias corroboram a ideia de que consumir crack é atentar contra a própria vida. É o caso do cartaz da exposição de fotos jornalísticas "Crack: dependência e morte", realizada em Curitiba (PR) durante o ano de 2009. O trabaIho fotográfico abarcou um período de cinco anos. O cartaz apresentou a imagem de um corpo ensanguentado com um cachimbo estrategicamente disposto à sua frente, como signo da morte pelo consumo da droga. Outro exemplo é a campanha movida pelo Sindicato das Empresas de Publicidade Exterior do Estado de São Paulo, 
no ano de 2012, com três mil outdoors distribuídos pelas cidades do estado e por mais de 40 rodovias com dizeres que parafraseiam o grito da independência: "Crack. Independência ou morte".

Durante a cerimônia de lançamento da campanha, a declaração do deputado Campos Machado, então líder do PTB na Assembleia Legislativa, é ilustrativa do ânimo com relação à questão do uso do crack e sua vinculação com a morte:

Pedimos aos publicitários uma campanha dramática, que mostrasse o tamanho do problema. Eles prepararam uma peça onde está escrito apenas: "Crack. Independência ou morte". Não precisa ser dito mais nada, não é? (Acontecendoonline, 2012).

Outra campanha, intitulada "Crack: a pedra da morte. Fique longe disso!" fez referência a um projeto de lei aprovado em alguns municípios gaúchos e de iniciativa da Ordem dos Advogados do Brasil (OAB), seccional daquele estado. O projeto determinou que

toda a documentação e manifestação dos agentes políticos e subordinados devem usar o termo "Pedra da morte" ao invés do crack (Bianchini, 2001).

As campanhas midiáticas levaram o público a conceber o uso de crack como risco de vida e obstáculo ao exercício do direito a ela. Lidar com usuários de crack passou assim a ser visto como atividade de manejo de situação de crise (Silva, 2012), o que corrobora certa literatura médica especializada. Em um dos capítulos de 0 tratamento do usuário de crack, Cláudio Jerônimo da Silva afirmou que a situação de crise compreende eventos "catastróficos" capazes de colocar em risco a vida do usuário e/ou de terceiros, entendidos, principalmente, como seus parentes e aqueles com quem coabita. Para a infelicidade dos frequentadores da Cracolândia paulistana, e de tantas outras pelo país, a situação de rua passou ser vista como risco e ameaça ao direito à vida:

[...] há uma tendência geral a se pensar que a crise se restrinja ao momento em que o paciente esteja em situação de rua, causando danos a si mesmo e colocando a família em risco, quando este momento representa apenas o auge da crise [...] (Silva, 2012: 404).

É como se nesse manual psiquiátrico, dedicado ao tratamento de usuários de drogas, o artigo 10 do Decreto $n$. o 24.559 de 1934, se transformasse em saber médico. A situação de rua aparece como suficiente para caracterizar uma crise, o que atentaria contra o direito à vida e abriria caminho para se revogar a liberdade. A decisão 
sobre o que deve ser considerado como risco à vida fica sob o arbítrio do médico. Sua autoridade não é alvo de discussão, a despeito de toda a complexidade que a constitui, e pode ser considerada uma caixa-preta ${ }^{1}$.

Sabemos o quanto uma crise pode nos informar sobre os elementos constitutivos da estrutura da situação da qual ela provém (Chateauraynaud, 1991). O social é apreensível por mostrar-se em sua condição incerta, indeterminada e problemática; não apenas adjudica visibilidade aos elementos característicos e basilares para os próprios atores envolvidos na situação, mas, deixa, por isso mesmo, que deles se produza um conhecimento e se conserve, ao mesmo tempo, imanente às suas atuações. Será por meio da descrição do modo como os atores experimentam e solucionam a crise que se poderá conceber e conhecer o que é o social para eles.

\section{A controvérsia em torno do uso do crack e seus desdobramentos eleitorais}

Em um levantamento das notícias sobre internação involuntária de usuários de crack, foi possível perceber a quase ausência do assunto na mídia até 2008, ano em que se divulgou o uso de cocaína pelo ex-jogador de futebol e apresentador esportivo Casagrande. Porém, desde 1998, notamos uma presença ostensiva de organizações, principalmente religiosas, relacionadas às clínicas de tratamento de usuários de drogas e às comunidades terapêuticas no debate público e governamental sobre o tema da internação involuntária (Vasconcelos, 2012).

Em 2009, com a intensificação do debate em torno do crack, inaugurou-se uma enfermaria com 28 leitos destinados a usuários de drogas, dentro de um hospital psiquiátrico. Tratava-se de uma parceria entre a Unidade de Pesquisa em Álcool e Drogas (Uniad), da Universidade Federal de São Paulo (Unifesp), a Secretaria da Saúde do Governo do Estado de São Paulo e o Grupo Saúde Bandeirantes/Hospital Lacan. A partir de 31 de março de 2009, a Uniad passou a coordenar essa unidade de enfermaria no Hospital Lacan, financiada pelo governo do estado de São Paulo e gerenciada pelo Grupo Saúde Bandeirantes. Na inauguração, esteve presente o Sr. José Serra, então governador do estado de São Paulo e futuro candidato à Presidência da República em 2010.

Em outubro do mesmo ano, o médico psiquiatra Ronaldo Laranjeira, da Uniad, alertou para a necessidade de as famílias atentarem para qualquer "comportamento errático" ou pródigo de seus membros, assim como o envolvimento com traficantes. Reclamou, também, da não aplicação da lei para internar involuntariamente:
1. O termo "caixapreta" foi retirado por Bruno Latour da cibernética e é utilizado para designar certo número de comandos muito complexos: "Em seu lugar, é desenhada uma caixinha preta, a respeito da qual não é preciso saber nada, senão o que nela entra e o que dela sai" (Latour, 2000: 14). 
Mas a família tem que se informar que existe uma lei que permite a internação involuntária. Mas essa lei não é seguida aqui no Brasil (Globo.com, 2009).

Na mesma matéria, o psiquiatra afirmou: "o Ministério da Saúde abandonou as famílias dos dependentes químicos". Essa declaração marcou o tom de um dos temas que predominaria no debate eleitoral presidencial do ano seguinte.

Em novembro do mesmo ano, a Prefeitura do Rio de Janeiro inaugurou três centros de atendimento destinados a usuários de crack com 60 vagas, sendo 40 para crianças e adolescentes e 20 para mulheres adultas. Em dezembro, o então ministro da Saúde lançou a Campanha Nacional de Alerta e Prevenção do Uso de Crack. Após a cerimônia de lançamento da campanha, ressaltou o fato de a lei permitir a internação do dependente involuntariamente "nos casos em que o paciente constitui um risco para si e para as pessoas em torno dele" (Chagas de Almeida, 2009). Novamente, foi acionado o Decreto n.o 24.559, de 3 de julho de 1934.

Os meses de mais acirrada disputa eleitoral foram também os de maior investimento midiático, político e empresarial na controvérsia em torno do crack. Com isso, criou-se uma verdadeira sinergia entre especialistas, universidades, mídia e políticos em busca de votos, conformando o momento crítico gerador da controvérsia. Entre agosto e novembro de 2010, o personagem Danilo - representado pelo jovem galã Cauã Reymond -, da novela Passione, da Rede Globo de Televisão, foi internado duas vezes de modo involuntário. Todo o drama familiar e amoroso serviu de pano de fundo para a defesa da internação involuntária.

Enquanto isso, na trama política, o candidato José Serra anunciou, em 27 de outubro de 2010, entre o primeiro e segundo turno da eleição presidencial, a pretensão de criar, caso eleito, um Ministério da Segurança e uma Guarda Nacional para proteção das fronteiras e coibição do contrabando de armas e drogas. Em seu programa político, observou ser o Brasil - segundo dados da Organização das Nações Unidas (ONU) - o país da América do Sul onde mais crescia o consumo de drogas. Nesse mesmo programa, Ronaldo Laranjeira, o já citado médico da Unifesp, alertou para o consumo crescente de crack e sua letalidade: "o crack mata mais que o câncer". "E o problema começa nas fronteiras, onde os traficantes agem livremente por falta de ação firme do governo federal", acrescentou Serra na ocasião. Piores seriam os efeitos devastadores da droga. "Para os dependentes químicos e suas famílias, o gesto do governo deve ser de oferecer tratamento, carinho e atenção" (Coligação: o Brasil pode mais, 2010). O programa televisivo de Serra destacou que, durante sua gestão como governador do estado, criou 
clínicas de recuperação de dependentes. Ao exibir a cerimônia de inauguração de uma dessas clínicas, em março de 2009, observamos, novamente, a presença do médico psiquiatra Ronaldo Laranjeira. Na sequência do programa televisivo, Serra declarou:

Nós temos que ter uma rede de clínicas como essa em todo o país. Temos que pôr o governo federal para apoiar essas clínicas (Coligação: o Brasil pode mais, 2010).

\section{As clínicas de tratamento e a internação involuntária de usuários de crack}

Para a compreensão da internação involuntária, a família é fundamental. É ela a responsável por solicitar a internação do usuário de drogas, particularmente daquele que consome crack. Em nome dos interesses familiares, manifestaram-se tanto os críticos como os defensores do Programa (Latour, 2001) que, lembremos, nesta controvérsia, consiste na internação maciça de usuários de crack. A crítica girou em torno dos direitos dos usuários de drogas e da desconfiança quanto às intenções da família e da instituição privada responsável pela internação. A família poderia desejar apenas se ver livre do usuário, salientaram alguns (Chagas de Almeida, 2009).

É o caso de um jovem homossexual, cuja condição desagradava os membros da família a ponto de procurarem interná-lo (Silva \& Zuba, 2009). Em 23 de janeiro de 2010, Alexandre de Araújo publicou no jornal Consultor Jurídico um artigo a respeito das internações involuntárias. Nele, o autor denunciava tanto os métodos violentos utilizados pelas empresas de remoção na internação à força de pessoas plenamente lúcidas - sem a presença de um médico para atestar a necessidade do procedimento - quanto o uso de celas fortes e a incomunicabilidade do interno (Araújo, 2010).

Os usuários de droga, internados por empresas de segurança a partir da requisição feita por entes familiares, tornaram-se objeto de uma negociação de prestação de serviços. Sedada e/ou amarrada, uma pessoa em pleno domínio das faculdades do juízo e da vontade pode ser contida em cela forte. O termo "contenção" é comumente utilizado na prática psiquiátrica para designar modos mecânicos e químicos de paralisar um paciente, tais como amarrá-lo em uma maca, caso seja considerado muito agitado, ou mesmo sedá-lo. Na internação involuntária, o médico, muitas vezes, atesta a posteriori a necessidade de internação, sem a obrigação de estar presente no momento da "remoção" ou "contenção". Porém, como apontou o psi- 
quiatra Francisco José dos Reis Goyatá, ainda em 2009, há uma justificativa perfeitamente plausível para o ato:

Na ocasião, o paciente não tinha controle sobre si, ameaçava sua integridade física, psíquica e moral e/ou colocava em risco a vida de terceiros. [...] É também um resguardo ao social que leva seu paciente a tratamento (Araújo, 2010).

Ao considerar o ato da remoção possibilitado pelo consentimento da família, devemos observar o embate, próprio da internação forçada, de vontades entre usuário/ família e, ainda, a maneira como é atualizado o recurso discursivo da "ameaça à integridade física dos familiares", pertencente ao Decreto $n$. o 24.559, de 3 de julho de 1934. O risco apontado por esse decreto - de os usuários de drogas "perturbarem a ordem ou ofenderem a moral pública" (Brasil, 1934) - fica reconfigurado em preocupação de garantir o "resguardo ao social".

O poeta e escritor Ataíde Lemos observou a necessidade do uso de drogas e da força na contenção do usuário involuntariamente sequestrado:

[...] uma entidade onde se obrigue alguém permanecer involuntariamente precisará escolher um de dois métodos; um é dopar o dependente químico constantemente, [...] o outro é usar da força [...] (Lemos, 2010).

Os manuais de psiquiatria confirmam o modo de contenção física e mecânica em hospitais psiquiátricos, além da contenção química com uso de medicamentos por via oral aos pacientes "colaborativos" e por via intramuscular para os "não colaborativos" (Pereira, 2009: 41).

\section{O Programa em ação}

A forma como clínicas e comunidades terapêuticas divulgam seus serviços na Internet tornou-se uma interessante fonte de informações sobre suas práticas. Permite-nos formar uma ideia de como recorrem à legislação e compõem a rede do

2. A fim de manter o sigilo das empresas, utilizaremos suas iniciais ao invés de seus nomes e não citaremos os sites que serviram de fonte à pesquisa.
Programa de Internação².

Na página da Clínica AT, uma tranquila paisagem campestre faz fundo para o logotipo da empresa, composto por duas mãos unidas em meio a circunferências azuis e verdes e o acréscimo das palavras "internação involuntária". Um trecho se destaca: "Uma resposta objetiva para os problemas de dependência química, de transtornos mentais e de comportamento". Parece claro que se trata de especificar a missão da 
empresa e certamente os propósitos de internação. O artigo 6으, parágrafo único, inciso II da Lei n. o 10.216/2001 - que trata da possibilidade de internação involuntária - abre a proposta da empresa sobre o assunto da seguinte maneira: "II- internação involuntária: aquela que se dá sem o consentimento do usuário e a pedido de terceiro". A seguir, versa sobre as possibilidades de tornar uma internação voluntária em involuntária, bastando para isso haver a "séria possibilidade de dano imediato ou iminente a pessoas ou a outros", ou pelo futuro interno apresentar, de alguma forma, um julgamento prejudicado. A internação se justifica ao se verificar doença mental ou risco de "autoagressão, heteroagressão, de agressão à ordem pública, de exposição social ou de incapacidade grave de autocuidados". A explicação prossegue informando ser do Ministério Público Estadual a responsabilidade pela fiscalização da clínica. Essa informação nada mais faz além de comunicar o artigo 8o da Lei n.․ 10.216 .

Na página da Clínica GVRH, vê-se a imagem de um relógio despertador com os seguintes dizeres: "Atendimento 24h. Ligue agora e não perca tempo!" Logo abaixo, listam-se cinco diferentes números de telefone, sendo um fixo e quatro celulares de todas as operadoras disponíveis no país naquela época, com o anúncio de tratar-se de contato de abrangência nacional. Depois das explicações sobre tratamento involuntário, encontra-se a foto de um veículo do tipo furgão, encimada pelo título "Serviço de Resgate 24 Horas em todo o Brasil", com o número 24 em destaque. O site alerta que o tratamento involuntário é destinado a "todos que necessitam de ajuda, mas demonstram não aceitar ajuda das pessoas que estão ao seu lado". Segundo o anúncio, a duração mínima do tratamento é de 150 dias, prorrogáveis por outros 150, a depender de avaliação médica. Novamente, o relacionamento difícil com os familiares é mostrado como motivo para a intervenção, assim como pelo fato de o usuário não estar "em condições de decidir se aceita ou não o tratamento". Há todo um discurso sobre internação compulsória que só aumenta a impressão de precariedade das bases do serviço ofertado às famílias:

A condição física não permite que o usuário venha para uma internação comulsória [sic], pois o seu corpo físico já não consegue mais ficar sem a droga.

O site da Clínica CD, localizada na cidade litorânea de Peruíbe (SP), chama a atenção por diversos fatores. Além da chamada para o atendimento 24 horas, veem-se a imagem de uma família sorridente, o nome da clínica e o logotipo, com os dizeres:

Tratamento para dependentes químicos. Internação voluntária e involuntária [e] a única clínica de internação involuntária do litoral paulista a funcionar de maneira legalizada (grifo no original). 
Logo abaixo do logotipo, há um grande banner do programa Repórter Record, especificamente do episódio "A epidemia que aterroriza o Brasil", com cenas gravadas na Clínica CD. O banner foi dividido em partes, sendo a primeira constituída por

cenas fortes que mostram o resgate de um dependente químico feito em local perigoso, o que, por motivos de segurança, levou a equipe da Clínica CD a agir descaracterizada, sem ambulâncias e uniformes brancos.

A Clínica CRCV dedica uma página inteira de seu site à internação involuntária. Margeado por uma paisagem campestre, o logotipo reproduz uma árvore cuja copa se encontra com as raízes. Ao lado deste, vem o anúncio "Remoção 24 h para todo o Brasil", bem como a promoção do serviço com pagamento facilitado "Melhor preço em internações. Facilitamos o seu pagamento em até 10 vezes". A foto da ambulância para remoção ocupa um grande espaço ao lado do texto sobre internação involuntária, que versa especificamente sobre o crack:

A dependência química, sobretudo em caso de drogas como o crack, costuma deixar o indivíduo refém da substância, sem a capacidade de avaliar o mal que ela faz a si e às pessoas que estão próximas.

O que faz parecer um retorno, de modo muito direto, à legislação implementada em 1934. Há um esforço para desqualificar o usuário de crack, especificamente como refém da droga, incapaz de fazer uma avaliação de sua condição e de todo dano causado à família, além de rejeitar o tratamento. Isso, aparentemente, o levaria à perda do direito de se negar a usufruir dos serviços prestados pela empresa de remoção e o faz passar à condição de objeto na transação comercial entre a família/cliente e a clínica/prestadora de serviço de remoção. Na realidade, um corpo/objeto sem vontade própria. Como um eletrodoméstico levado ao conserto, pode ser um pouco difícil transportá-lo até a oficina, mas, a empresa - possivelmente, uma terceira e não a clínica contratada - se encarrega da remoção:

Há casos em que o dependente químico já passou por uma série de internações voluntárias em comunidades terapêuticas, [por] grupos de autoajuda, sem sucesso e por isso não [quer] mais se tratar, por mais que o problema persista.

Mesmo nos casos de insucesso reiterado, o procedimento, apesar da ausência de impacto após uma série de internações, deve ser repetido, aparentemente, ad infinitum: 
Nestas ocasiões, a internação involuntária também é recomendada, desde que realizada por profissionais capacitados, em clínica especializada no tratamento.

Assim como as demais, a página da Clínica GV-RH sobre tratamento involuntário fornece o número de telefone de um plantão 24 horas. O esquema terapêutico é praticamente universal, indicado para "todos os que necessitam ajuda, mas, não aceitam". O objetivo das informações é, prioritariamente, transmitir uma ideia de segurança e legalidade aos serviços propostos pela clínica, prometendo ofertar o serviço "mais seguro do Brasil".

\footnotetext{
Garantimos a integridade tanto física quanto psicológica de nossos pacientes, com uma abordagem segura e uma viagem tranquila. Dentro de nossa unidade de tratamento, garantimos esta integridade total. [...] Pois abominamos atitudes tais como choques, amarras, lutas físicas, confinamentos, isolamentos etc.
}

A garantia de segurança aos familiares está em uma cláusula contratual devidamente destacada. O site alerta os familiares a não perderem tempo: "solicite um tratamento involuntário antes que seja tarde!" Essas garantias nos parecem estar de alguma forma relacionadas às recorrentes preocupações dos familiares quanto ao tratamento dispensado nessas clínicas e à ocorrência de maus-tratos. Esta é uma inquietação das famílias a ponto de, no site da empresa, as informações virem em destaque. Inquietação que se agudiza com as denúncias de maus-tratos feitas em relatório da Comissão Nacional de Direitos Humanos do Conselho Federal de Psicologia (Conselho Federal de Psicologia, 2011).

A internação involuntária se inicia a partir de processo de convencimento exercido pela clínica sobre a família para que consinta na internação ou, inversamente, por pedido da família à clínica/comunidade terapêutica. A remoção obtém força legal e moral pelo pedido ou concordância familiar e pela assinatura de um contrato no qual se estabelecem cláusulas de garantia da integridade do futuro interno. O contrato serve, também, como garantia à família contra possíveis ações no campo jurídico do usuário de drogas contra ela. Nesse documento, a família se compromete a pagar os encargos previstos. É importante frisar que, a partir da contratação família/ clínica, e não da avaliação médica do futuro paciente, é que a violência pode ser legitimamente exercida. A avaliação médica é, geralmente, a posteriori, uma formalidade a ser cumprida por ocasião da visita do médico à clínica, se e quando houver.

Uma justificativa possível para o consentimento familiar pode ser encontrada na alegação de que o usuário de drogas - e mais especificamente do crack - coloca 
sua vida em risco. Há pouca relação com a legislação atual, Lei n.o 10.216, mas, tem certa consonância com a Lei n.o 24.559, de 1934. O estado de abandono é mencionado nessa lei como justificativa para internação em estabelecimento aberto, porém, apenas se não houver recusa formal por parte do paciente. Os estabelecimentos fechados se destinariam somente aos detidos por autoridade policial ou internados por determinação judicial. O que na Lei n.o 24.559 era considerado estado de abandono encontra-se na atualidade na situação de rua. Porém, na década de 1930, os estabelecimentos fechados eram reservados aos então chamados toxicômanos de certa forma violentos. Isso se for possível inferir algum tipo de violência pelo termo "reações perigosas", constante da referida lei. Atualmente, na prática, ao usuário de crack é reservado o direito de aceitar "ajuda" e passar a ser o objeto da transação comercial família/clínica. Até então, a avaliação médica encontra-se dispensada.

A Lei n.o 24.559 é muito mais cuidadosa em relação à prática atual, pois o médico responsável pelo requerimento para uma internação não poderá ser o mesmo a fornecer o atestado para possibilitar a entrada do paciente em instituição dedicada à "profilaxia mental".

Vimos no material proveniente das páginas das comunidades terapêuticas na Internet que é a partir do consentimento familiar que se inicia o processo de busca e captura do usuário, pela equipe de remoção, com sua retirada da cena de uso, da residência ou de outro local onde se encontra, para ser deslocado até a clínica.

Na condição de dependente, ele não procura nem usa drogas por vontade própria, mas, apenas por ser "escravo do vício", por viver em ambiente marcado pela controvérsia, pelo risco e pela crise. De escravo do vício a paciente, o usuário mantém-se em uma constante alienação atribuída por terceiros. Argumentamos - em outra ocasião - que todo usuário de crack exerce algum nível de controle sobre seu uso (Alves, 2016); só o perde completamente quando é submetido à lógica da internação involuntária, após ser contido quimicamente.

Na reunião de apresentação do relatório final da Subcomissão Temporária de Políticas Sociais sobre Dependentes Químicos de Álcool, Crack e Outras Drogas do Senado Federal, realizada em 13 de dezembro de 2011, Emmanuel Fortes, o representante do Conselho Federal de Medicina (CFM), defendeu a internação involuntária:

A vida é um bem indisponível. E a liberdade, embora tutelada pela Constituição, é uma conquista que não pode ser exercida de qualquer maneira (CFM, 2011). 
O Dr. Fortes insistiu no argumento, caudatário da legislação de 1934, de sobrepor a vida à liberdade. Entendida dessa forma, a defesa da vida do usuário de drogas passava a ser o apanágio de outro - o médico - e este passa a exercer sobre o usuário um poder de polícia, independentemente da vontade do paciente cuja vida o médico considera em risco. Havia também interesses comerciais das comunidades terapêuticas em formar uma clientela cativa, não no sentido de quem foi cativado, mas literalmente na perspectiva daquele que é colocado em cativeiro. Uniam-se, assim, os interesses das clínicas aos interesses da corporação médica, não poucas vezes contando entre seus membros proprietários de clínicas de tratamento, todos na cruzada para promover a defesa da vida por meio da internação ou da contenção involuntária. Enfim, a materialização do Programa. O Dr. Fortes também citou a Lei n. 10.216, ao falar da fiscalização a cargo do Ministério Público (Mendes \& Menezes, 2013).

Em agosto de 2011, o CFM havia lançado o folder "Diretrizes gerais médicas para assistência integral ao dependente do uso do crack", em cuja capa se mostrava um usuário de pele parda segurando de modo inclinado um cachimbo industrializado, com a chama do isqueiro acesa para a fusão e posterior vaporização da pedra de crack. No documento, as comunidades terapêuticas foram descritas da seguinte forma:

Os serviços comunitários, geralmente religiosos, são muitos, são precários, carecem de base científica e beneficiam pouco o dependente químico (CFM, 2011).

No mesmo documento, os usuários de crack eram igualados à condição de dependentes químicos, não havendo espaço, segundo o CFM, para outros padrões de uso da substância. Não eram só dependentes - ou seja, passíveis da internação involuntária -, mas, também, deviam carregar o estigma adicional de sustentáculos do tráfico de drogas com todas as suas mazelas de criminalidade: "Os usuários recreativos, que sustentam o tráfico, são vistos pela Lei n. 11.343/2006 como dependentes" (CFM, 2011).

O estado de Minas Gerais planejou implantar a internação involuntária maciça com auxílio dos consultórios de rua:

A principal ferramenta para a ampliação dessas ações serão os chamados "consultórios de rua" [...] em áreas urbanas com mais de 100 mil habitantes invadidas por consumidores de drogas e traficantes (Parreiras \& Sarapu, 2011). 
Os usuários de drogas, além da alcunha de zumbis, receberam uma nova designação estigmatizante (Wurdig \& Motta, 2014) por parte do jornal Estado de Minas: a de "invasores". Assim, o consultório de rua, originalmente pensado como instrumento de levar saúde aos excluídos, foi transmutado em aparato policialesco contra "pacientes invasores graves". Não à toa, o nome da ação mineira é Programa Rua Livre, liberdade para a rua, um lugar, à custa da liberdade do usuário de crack, uma pessoa. O governo daquele estado estaria, naquele momento, financiando 3.000 dos 4.500 internos de Minas em clínicas de recuperação de usuários de drogas.

A questão de cunho axiológico que negava o direito à liberdade, em nome da proteção à vida, aflorou no momento crítico da controvérsia em que situações rotineiras e habituais, como a remoção dos usuários de crack, tornaram-se manifestas, demandando, para sua justificação, verdadeiras investigações concernentes ao justo (Boltanski \& Thévenot, 1991).

Essa crítica social estava disseminada na controvérsia sobre a crítica da situação de abandono a que a família estava exposta pela inação dos governos ou a crítica da violência do Estado praticada sobre usuários de drogas que não eram psicóticos e, portanto, não deveriam estar internados involuntariamente. Expunham-se, assim, as competências críticas dos atores que procuramos formalizar (Boltanski, 1990). Para encarcerar maciçamente foi necessário igualar o uso do crack à morte e, posteriormente, impor a vida como valor sobre a liberdade.

\section{O Antiprograma reage}

Em 2011, a Agência Nacional de Vigilância Sanitária (Anvisa) publicou uma resolução sobre os

requisitos de segurança sanitária para o funcionamento de instituições que prestem serviços de atenção a pessoas com transtornos decorrentes do uso, abuso ou dependência de substâncias psicoativas (Anvisa, 2011).

Essa importante resolução veio estabelecer padrões mínimos para o funcionamento das clínicas de tratamento e das comunidades terapêuticas, determinando ser a convivência entre os pares o principal instrumento terapêutico para o tratamento dos usuários de drogas com transtornos. Também impôs a obrigatoriedade de a clínica manter um responsável técnico pela instituição, de desenvolver ações de capacitação para as equipes e de proibir o uso de trancas, ou mesmo de chaves, para conter os pacientes. 
A possibilidade de o usuário de drogas interromper o tratamento permanece interditada em caso de

risco imediato de vida para si e ou para terceiros ou de intoxicação por substâncias psicoativas, avaliadas e documentadas por profissional médico (Anvisa, 2011).

Isto mantém, na prática, certa lógica da legislação de 1934, com o agravante de acrescentar o presumível consumo de drogas como justificativa à impossibilidade de abandonar o tratamento.

Em muitos casos, uma primeira internação involuntária acaba sendo, para os usuários de crack, apenas a porta de entrada para múltiplas internações, ou seja, eles são sujeitos, em sua história de vida, a até dezenas de internações em clínicas terapêuticas. Isso seria a comprovação de ser a internação involuntária "uma resposta estereotipada ao comportamento desviante do usuário de drogas" (Kimati, 2011). A dificuldade de estipular claramente os limites, quando se pode afirmar algo confiável a respeito da perda de capacidade de discernimento deste ou daquele usuário de drogas, abre espaço para que as sucessivas internações resultem em uma crescente intolerância familiar. Cada novo fracasso acaba por retroalimentar o descrédito familiar com o usuário de crack e por gerar novas internações.

No final de 2012, uma importante polêmica se estabeleceu entre, de um lado, Alexandre Padilha, o então Ministro da Saúde, e Salomão Rodrigues, diretor da Associação Brasileira de Psiquiatria (ABP) e presidente do Conselho Regional de Medicina de Goiás (CRM-GO), e, de outro, Clara Goldmann, do Conselho Federal de Psicologia (CFP). O ministro defendeu a internação involuntária para usuários com risco de morte e foi apoiado por Rodrigues, para quem internar alguém involuntariamente não é retirar sua liberdade, mas garantir a vida.

No lançamento do programa "Crack, é possível vencer", o ministro Padilha incluiu os consultórios na rua em sua iniciativa de internação involuntária (Estadão, 2011). Por sua vez, Clara Goldmann apoiou o tratamento na rede Centro de Atenção Psicossocial (Caps) e colocou em dúvida a viabilidade de sucesso de um tratamento não pactuado com o paciente. Esse debate marcou uma posição recorrentemente diferenciada entre as entidades representativas dos psiquiatras e dos psicólogos. Em dezembro de 2012, o ministro da Saúde advogou por diversas vezes a internação involuntária em um quadro nacional, considerado por ele característico de uma "epidemia de crack" (Moura \& Monteiro, 2011), com o uso dos consultórios na rua para promover a avaliação dos casos de internação. 
A controvérsia continuou ainda aquecida com o posicionamento público de Antônio Nery Filho, criador do primeiro consultório "de" rua do país, na capital baiana. Os termos consultório "de" ou "na" rua denotam diferenças quanto à concepção desses serviços. Ambos propõem um

atendimento especializado em saúde à população considerada em situação de rua, exposta a usos variados de substâncias psicoativas (Nery Filho, Valério \& Monteiro 2011: 17),

porém, o primeiro seria composto por equipes com maior autonomia em relação aos serviços ambulatoriais de saúde. O plano de internação involuntária a partir de consultórios na rua seria, na opinião de Antônio Nery Filho, um retrocesso e um desvio de foco de problemas mais sérios como o do abuso de álcool, tabaco, medicamentos e psicoativos voláteis. Suas preocupações concentravam-se na exclusão social da população em situação de rua e em sua incapacidade de acessar os serviços de saúde, refletindo, juntamente com as ideias de Clara Goldmann, importantes aspectos do Antiprograma. Ele desqualificou tecnicamente a iniciativa e a acusou de ser um processo de higienização:

\begin{abstract}
Sou radical e frontalmente contra a internação involuntária, sobretudo de pessoas que usam drogas na rua e não estão psicóticas, não perderam a capacidade de entendimento e determinação ( $\mathrm{Nu}$ blat \& Sadi, 2011).
\end{abstract}

Para Nery Filho - e inversamente ao discurso supracitado de Capez -, os usuários de crack não perderam seu entendimento, tampouco sua capacidade de autodeterminação por estarem na rua, a não ser no caso de estarem psicóticos. O médico ainda criticou o modelo religioso ou espiritual de tratamento de usuários de drogas:

\footnotetext{
Por trás disso tem o movimento das comunidades terapêuticas. A maioria é de caráter religioso. As pessoas não suportam rezar o dia todo e achar que Jesus vai substituir o crack, a cocaína, o álcool ou qualquer coisa do tipo (Nublat \& Sadi, 2011).
}

Ainda em dezembro de 2011, o CFP lançou um panfleto intitulado "13 razões para defender uma política para usuários de crack, álcool e outras drogas sem exclusão". Nele, esse conselho defendeu os seguintes pontos básicos do Antiprograma:

i. ações no âmbito do SUS, ou seja, públicas e não privadas;

ii. participação do usuário;

iii. serviços de atenção, como a rede Caps; 
iv. leitos em hospitais gerais;

v. casas de acolhimento transitório e consultórios na rua, em detrimento dos manicômios e das comunidades terapêuticas; e,

vi. o princípio da redução de danos.

O documento combatia a imposição de crenças religiosas por parte das comunidades terapêuticas confessionais, o estigma do usuário perigoso, irrecuperável e monstruoso, a caracterização epidêmica do uso do crack e a inclusão das comunidades terapêuticas nas políticas públicas.

O panfleto refletia as conclusões de um importante levantamento feito pelo CFP em 68 instituições em 24 estados da Federação e no Distrito Federal a respeito da situação dos locais de internação dos usuários de drogas. Esse levantamento gerou um documento de 200 páginas com denúncias diversas sobre as condições das comunidades terapêuticas e clínicas, em grande parte vinculadas a grupos religiosos. O texto reconhecia que "o debate sobre o tema das drogas [fora] alçado à condição de principal problema social do país" (CFP, 2011) e alertava para os riscos de segregação advindos da crença em uma epidemia do crack (Nappo, Sanchez \& Ribeiro, 2012) e de seu corolário, a internação involuntária.

\section{Programa e Antiprograma: atores em controvérsia}

Vimos, neste artigo, como, a partir do mapeamento da controvérsia em torno da internação involuntária de usuários de drogas, particularmente do crack, pessoas e instituições são afetadas e colocadas em movimento, seja por uma crise a ser debelada ou por situações consideradas de risco. Evidentemente, como alertou Latour (2012), é impossível esgotar um tema. Os fluxos, as conexões e os agenciamentos são mais complexos do que podemos registrar nesse itinerário. As relações entre instituições, as diversas formas de conexões estabelecidas, as leituras dessa polêmica que se alastram na Internet, em chats, grupos de discussão, as respostas oficiais à controvérsia em forma de padronização das terapêuticas são dimensões que não se consegue abordar completamente. O desafio em seguir os itinerários, adentrando as tortuosas cartografias das controvérsias, é onde parar e evitar o perigo de traçar - sob o sorriso de Borges - um mapa do tamanho do mundo.

Ao seguir os atores implicados em torno da internação involuntária, procuramos as agências capazes de levar instituições e indivíduos a agirem diante da crise gerada 
pelo uso do crack. Para tanto, buscamos descrever as controvérsias em torno da internação involuntária e, através delas, rastrear as conexões sociais entre os grupos propiciadas por seus "porta-vozes" (Latour, 2012: 55). Pudemos perceber como entidades de classe - a exemplo da Ordem dos Advogados do Brasil e suas seccionais regionais, dos conselhos de classe (de psicologia e psiquiatria) - se valem de seus presidentes nacionais e regionais para Ihes dar voz e assim defini-los, tanto quanto são definidos por suas resoluções, diretrizes e mesmo panfletos.

Tanto os políticos e demais atores humanos como as leis, os artigos de revistas especializadas, os capítulos de manuais de tratamento de usuários de crack, as matérias jornalísticas publicadas na grande mídia e os panfletos veiculados por diferentes entidades de classe, são todos atores por fazer outros fazerem. Nesse sentido, a partir desses diversos atores e seguindo-os pela rede sociotécnica, pudemos verificar que certos itens em discussão na controvérsia e seus pontos já estão estabilizados como caixas-pretas.

Um exemplo de caixa-preta nesta controvérsia é o da autoridade do psiquiatra para internar involuntariamente os usuários de crack sob o risco de colocar suas vidas em perigo ou as de outras pessoas. Esse poder (ou dever?) não é colocado em discussão. No entanto, os manuais de tratamento de usuários de crack insistem na equiparação situação de rua/risco de vida; procuram transformar esta associação numa caixa-preta, enquanto conselhos profissionais, como o Conselho Federal de Psicologia, são levados a agir para não permitir a estabilização desta discussão. Os atuantes estendem mais ou menos a rede para estabilizar e instabilizar caixas-pretas, outros agentes e seus aliados. As comunidades terapêuticas, por exemplo, podem ter problemas em estender a rede até a Associação Brasileira de Psiquiatria, que é favorável à internação involuntária, porém, contrária à sua realização fora dos hospitais e das clínicas de recuperação.

A ideia disseminada da epidemia do consumo de crack ensejou no país a consciência de estarmos todos em risco. Afinal, qualquer um poderia tornar-se familiar de um usuário de crack ou ser vítima de um criminoso em busca de fundos para sustentar seu vício. O que seria feito daí por diante dependeria dos acordos a serem estabelecidos pelos atores nos momentos críticos da controvérsia. Esses acordos seriam capazes de produzir e transformar o social.

Esses acontecimentos parecem refletir uma prática política de governar fora das regras, utilizando o primado da ciência como justificativa para a adoção de medidas políticas na defesa de interesses privados, em detrimento do processo democrático e do próprio Estado de direito. Os eventos podem ser entendidos como reflexo de 
uma técnica de governo, legitimada muito mais por uma recriação da desordem do que pela manutenção da ordem.

Os atores-rede desta controvérsia em torno da internação involuntária de usuários de crack estabelecem certas relações entre si nas quais agem como mediadores, ou seja, "fazem os outros realizarem coisas inesperadas" (Latour, 2012: 158). Todos, portanto, associam-se e transformam-se. Na controvérsia em torno da internação compulsória de usuários de crack, algumas alianças vão se constituindo. Como a do psiquiatra da Uniad, Ronaldo Laranjeira, e do político José Serra, em torno da defesa, promoção e mesmo da elaboração de políticas públicas sobre drogas, deste político, quando no governo do estado de São Paulo e quando candidato à Presidência do país. Ou ainda, a aliança entre este mesmo Ronaldo Laranjeira e as clínicas de tratamento de usuários de drogas e as comunidades terapêuticas na defesa da internação involuntária.

A conceituação presente na legislação de 1934 é constantemente resgatada para justificar a internação involuntária em comunidades terapêuticas, porém, o que pode ser considerado inesperado é que o Conselho Regional de Psicologia de São Paulo, contrário a esta modalidade de intervenção, se utilize do discurso presente nesta lei com princípios análogos aos dos defensores do encarceramento psiquiátrico, como o deputado Fernando Capez.

As entidades de classe, por sua vez, são instadas a defrontar-se com políticas públicas expressas em protocolos e programas elaborados pelos três entes federativos, assim como em propostas de mudanças na legislação e em diferentes maneiras de aplicar a existente, diante do que se considerava uma crise. De modo análogo, unidades de pesquisa e de intervenção universitárias - como a Uniad - formam novos especialistas segundo suas diferentes visões a respeito da questão das drogas e se posicionam em defesa ou no ataque a políticas públicas e a propostas de mudanças na legislação. Os programas universitários também apresentam os seus porta-vozes, que são levados a agir de forma deslocada, ou seja, sob a influência da ação de outros. São os atores-rede: a origem de suas ações advém de suas conexões nessa rede, razão pela qual se constituem em uma constante fonte de incerteza. Os políticos presentes na controvérsia agem sob influência uns dos outros. A descrição dessa controvérsia feita neste texto traz a possibilidade de delinear algo dessas associações entre os atores.

A esperança geral deste texto é a de que essa controvérsia possa revelar algo a respeito da forma que escolhemos para organizar nossas vidas, principalmente em situações que envolvem dimensões importantes de experiências vitais. 


\section{Referências}

ABREU, Cristiane; VAL, Eduardo Manuel. Fundamentos constitucionais da internação involuntária do dependente químico. Revista do Instituto do Direito Brasileiro, Ano 2, n. 10: 10565-10593, 2013. Disponível em: <http://www.idb-fdul.com/>. Acesso em: 9 Fev. 2017.

ACONTECENDOONLINE. "Acontecendo em Minas Gerais". IPATINGABLOGSPOT. 11 abr. 2012. Disponível em: <http://ipatingablogspotcom.blogspot.com.br/2012/04/ lancada-campanha-crack-independencia-ou.html>. Acesso em: 29 Abr. 2014.

AGÊNCIA NACIONAL DE VIGILÂNCIA SANITÁRIA (ANVISA). RDC no 29, de 30 Jun. 2011. Dispõe sobre os requisitos de segurança sanitária para o funcionamento de instituições que prestem serviços de atenção a pessoas com transtornos decorrentes do uso, abuso ou dependência de substâncias psicoativas. Diário Oficial da União. 30 Jul. 2011. Disponível em: <http://bvsms.saude.gov.br/bvs/saudelegis/anvisa/2011/res0029_30_06_2011.html>. Acesso em: 09 Fev. 2017.

ALVES, Ygor. O uso do crack como ele é: o cachimbo, o "bloco" e o usuário. Etnográfica [online], v. 20, n. 3, 2016 [online desde 27 Nov. 2016]. URL: <http://etnografica. revues.org/4640>. Acesso em: 28 Nov. 2016.

—_. Internação involuntária de usuários de crack. 07 Ago. 2012. Disponível em: <http://prezi.com/kku2kzve4i94/internacao-involuntaria-de-usuarios-de-carck/>. Acesso em: 06 Maio 2014.

ARAÚJO, Alexandre Arnaut. Poucas clínicas seguem rigorosamente a lei. Consultor Jurídico, 2010. Disponível em: <http://www.conjur.com.br/2010-jan-23/clinicas-seguem-lei-internacao-doente-usuario-droga>. Acesso em: 07 Maio 2014.

BARROS, Daniel Martins de; SERAFIM, Antônio de Pádua. Parâmetros legais para a internação involuntária no Brasil. Revista de Psiquiatria Clínica, v. 36, n. 4: 175-177, 2009.

BIANCHINI, Deputado Estadual Bombeiro. Pedra da morte! Magazine, 14 Jun. 2001. Disponível em: <http://miguelbianchini.blogspot.com.br/2001_06_01_archive. html>. Acesso em: 29 Abr. 2014.

BOLTANSKI, Luc. L'amour et la justice comme compétences: trois essais de sociologie de l'action. Paris: Métailié, 1990.

BOLTANSKI, LUC; THÉVENOT, Laurent. De la justification: les économies de la grandeur. Paris: Gallimard, 1991. 
BRASIL. Decreto n. 24.559, de 3 de julho de 1934. Dispõe sobre a profilaxia mental, a assistência e proteção à pessoa e aos bens dos psicopatas, a fiscalização dos serviços psiquiátricos e dá outras providências. Lista texto integral, 1934. Disponível em: $\quad<$ http://legis.senado.gov.br/legislacao/ListaTextolntegral.action?id=20366\&norma=35529>. Acesso em: 23 Abr. 2014.

CAPEZ, Fernando. Drogas: internação compulsória e educação. Folha de S. Paulo, São Paulo, 19 Jul. 2011. Disponível em: <http://www1.folha.uol.com.br/fsp/opiniao/fz1907201108.htm>. Acesso em: 25 Maio 2014.

CHAGAS DE ALMEIDA, Baptista. Ministro da Saúde alerta para o crack, droga que tem oferta abundante e preço baixo, tornando-se acessível. Correio Braziliense. Brasília, 17 Dez. 2009. Disponível em: <http://www.correiobraziliense.com.br/app/noticia/brasil/2009/12/17/internas_polbraeco,161492/ministro-da-saude-alerta-para-o-crack-droga-que-tem-oferta-abundante-e-preco-baixo-tornando-se-acessivel. shtml>. Acesso em: 10 Fev. 2017.

ChATEAURAYNAUD, Francis. La faute professionnelle. Paris: Metailié, 1991.

COELHO, Isabel; OLIVEIRA, Maria Helena Barros de. Internação compulsória e crack: um desserviço à saúde pública. Saúde em Debate, v. 38, n. 101, p. 359-367, 2014.

COLIGAÇÃO: O BRASIL PODE MAIS. Programa Serra Presidente, 2010. Disponível em: <https://www.youtube.com/watch?v=wHNKb4_OSJY>. Acesso em: 16 Abr. 2014.

CONSELHO FEDERAL DE PSICOLOGIA (CFP). Relatório da 4ạ Inspeção Nacional de Direitos humanos: locais de internação para usuários de drogas. Brasília: Conselho Federal de Psicologia, 2011.

CONSELHO REGIONAL DE PSICOLOGIA DE SÃO PAULO (CRPSP). Folder. Página do Conselho Regional de Psicologia de São Paulo. São Paulo, 2013. Disponível em: <http://www.crpsp.org.br/PORTAL/comunicacao/artes-graficas/internacao_compulsoria/internacao_compulsoria_verso.pdf>. Acesso em: 04 Fev. 2014.

DALSENTER, Fernanda Bunese; TIMI, Jorge Rufino Ribas. O embasamento legal do internamento compulsório de dependentes químicos. Percurso, v. 12, n. 1, p. 5-20, 2012.

DE AGUIAR PINHEIRO, Gustavo Henrique. O devido processo legal de internação psiquiátrica involuntária na ordem jurídica constitucional brasileira. Revista de Direito Sanitário, v. 12, n. 3, p. 125-138, 2013.

DE FRANÇA, Genival Luiz. Internação compulsória do dependente químico: violação do direito de liberdade ou proteção do direito à vida? Intertem@s, v. 24, n. 24, 2012. 
DELGADO, Paulo. Saúde mental e direitos humanos: 10 anos da Lei 10.216/2001. Arquivos Brasileiros de Psicologia, v. 63, n. 2, p. 114-121, 2011.

ESTADÃO. Dilma lança pacote de R\$ 4 bilhões contra crack. UOL Notícias, 07 Dez. 2011. Disponível em: <http://noticias.uol.com.br/ultimas-noticias/agencia/2011/ 12/07/dilma-lanca-pacote-de-r-4-bilhoes-contra-crack.jhtm>

FIORE, Mauricio. Uso de "drogas": controvérsias médicas e debate público. Campinas (SP): Mercado de Letras, 2007.

GLOBO.COM. Especialistas discutem o vício em crack. Rio de Janeiro, 26 Out. 2009. Disponível em: <http://jornalnacional.globo.com/Telejornais/JN/0,MUL135569410406,00-especialistas+discutem+o+vicio+em+crack.html>. Acesso em: 07 Maio 2014.

KERR PONTES, Alexandre; SANTOS MEZA, Ana Paula; GASTALHO DE BICALHO, Pedro Paulo. Ciência e política das drogas: as controvérsias em torno das políticas públicas de internação compulsória. Estudos e Pesquisas em Psicologia, v. 15, n. 4, p. 14331450, 2015.

KIMATI, Marcelo. Internações involuntárias, compulsórias e o papel do Estado. Radis na Rede. 6 Out. 2011. Disponível em: <http://www6.ensp.fiocruz.br/radis/radis-na-rede/internacoes-involuntarias-compulsorias-e-o-papel-do-estado>. Acesso em: 22 Maio 2014.

LATOUR, Bruno. Reagregando o social: uma introdução à teoria do ator-rede. Salvador (BA); Bauru (SP): EdUFBA; Edusc, 2012.

. A esperança de Pandora. Bauru (SP): Edusc, 2001.

LEMOS, Ataíde. Internação involuntária é sinônimo de prisão. Recanto das Letras, 5 Maio 2010. Disponível em: <http://www.ataide.recantodasletras.com.br/blog. php?idb=22668>. Acesso em: 10 Fev. 2017.

MACEDO, Fernanda dos Santos de; ROSO, Adriane; LARA, Michele Pivetta de. MuIheres, saúde e uso de crack: a reprodução do novo racismo na/pela mídia televisiva. Saúde e Sociedade, v. 24, n. 4, p. 1285-1298, 2015.

MENDES, Vanessa Correia; MENEZES, Joyceane Bezerra de. O tratamento psiquiátrico e direitos humanos: uma análise dos instrumentos de controle da internação involuntária. Revista Direitos Fundamentais \& Democracia, v. 14, n. 2, p. 458-481, 2013. 
MONTEIRO, Hildenete Fortes. A internação psiquiátrica compulsória: uma abordagem à luz dos direitos fundamentais. Dissertação (Mestrado em Direito) - Pontifícia Universidade Católica do Rio Grande do Sul, Porto Alegre, Rio Grande do Sul, 2015.

MOURA, Rafael Moraes; MONTEIRO, Tânia. Pacote do governo prevê internação involuntária de usuários de crack. Estadão/Brasil. São Paulo, 07 Dez. 2011. Disponível em: <http://www.estadao.com.br/noticias/geral, pacote-do-governo-preve-internacao-involuntaria-de-usuarios-de-crack,807926,0.htm>. Acesso em: 12 Fev. 2017.

NAPPO, Solange Aparecida; SANCHEZ, Zila; RIBEIRO, Luciana Abeid. Is there a crack epidemic among students in Brazil? Comments on media and public health issues. Cadernos de Saúde Pública, v. 28, n.9, p. 1643-1649, 2012.

NERY FILHO, Antônio; VALÉRIO, Andréa Leite Ribeiro; MONTEIRO, Luiz Felipe. Guia do projeto consultório de rua. Salvador: Senad; Cetad, 2011.

NOVAES, Priscila Simara. O tratamento da dependência química e o ordenamento jurídico brasileiro. Revista Latinoamericana de Psicopatologia Fundamental, v. 17, n. 2, p. 342-356, 2014.

NUBLAT, Johanna; SADI, Andréia. Governo erra ao focar o crack, diz médico. Folha de S. Paulo, 11 Dez. 2011. Disponível em: <http://www1.folha.uol.com.br/fsp/cotidian/14281-governo-erra-ao-focar-o-crack-diz-medico.shtml>. Acesso em: 23 Maio 2014.

PARREIRAS, Mateus; SARAPU, Paula. Internação involuntária. País terá 308 consultórios de rua formados por profissionais de saúde que decidirão se o dependente apresenta risco para si e para a sociedade e precisa ser internado. Estado de Minas, Belo Horizonte, 08 Dez. 2011. Disponível em: <http://impresso.em.com.br/app/ noticia/cadernos/gerais/2011/12/08/interna_gerais,17184/>. Acesso em: 12 Fev. 2017.

PEREIRA, Alexandre de Araújo. Diretrizes gerais para o uso de contenção química. In: Araújo A. P. de (Org.). Diretrizes clínicas para atuação em saúde mental na atenção básica, p. 40-41. Belo Horizonte: Nescon/UFMG, 2009.

PINHEIRO, Gustavo Henrique. O devido processo legal de internação psiquiátrica involuntária na ordem jurídica constitucional brasileira. Revista de Direito Sanitário, v. 12, n. 3, p. 125-138, 6 Mar. 2013. Disponível em: <https://doi.org/10.11606/ issn.2316-9044.v12i3p125-138>.

PITTA, Ana Maria Fernandes. Um balanço da reforma psiquiátrica brasileira: instituições, atores e políticas. Ciência \& Saúde Coletiva, v. 16, p. 4579-4589, 2011. 
PONTES, Alexandre Kerr; MEZA, Ana Paula Santos; BICALHO, Pedro Paulo Gastalho de. Ciência e política das drogas: as controvérsias em torno das políticas públicas de internação compulsória. Estudos e Pesquisas em Psicologia, v. 15, n. 4, p. 14331450, 2015.

RUIZ, Viviana Rosa Reguera; MARQUES, Heitor Romero. A internação compulsória e suas variáveis: reflexões éticas e socioculturais no tratamento e reinserção do paciente na sociedade. Rev. Psicol. Saúde [online], v. 7, n. 1, p. 1-7, 2015.

SILVA, C. Manejo em situações de crise. In: RIBEIRO, Marcelo; LARANJEIRAS, Ronaldo (Orgs.). O tratamento do usuário de crack. 2. ed, p.404-411. Porto Alegre: Artmed, 2012.

SILVA, Andréa; ZUBA, Fernando. Drama familiar vira negócio rentável para clínicas. O Tempo. "Caderno Cidades", 15 Nov. 2009. Disponível em: <http://www.otempo. com.br/cidades/drama-familiar-vira-neg\%C3\%B3cio-rent\%C3\%A1vel-para-cl\%C3\%ADnicas-1.254186>. Acesso em: 10 Fev. 2017.

UNIVERSO ON LINE. Psicóloga que mora em Higienópolis nega autoria do termo "gente diferenciada". UOL Notícias. São Paulo, 13 Maio 2011. Disponível em: <http://noticias.uol.com.br/cotidiano/ultimas-noticias/2011/05/13/psicologa-da-frase-sobre-gente-diferenciada-em-higienopolis-nega-autoria.htm>. Acesso em: 05 Jun. 2014.

VASCONCELOS, Eduardo Mourão. Cenário econômico, social e psicossocial no Brasil recente, e a crescente difusão do crack: balanço e perspectivas de ação. "O Social em Questão". Revista de Departamento de Serviço Social da PUC-Rio, Ano XV, n. 28, p. 149-186, 2012.

VENTURINI, Tommaso. Diving in magma: how to explore controversies with actor-network theory. Public Understanding of Science, v. 19, n. 3, p. 258-273, 2010.

WURDIG, Karolina Kuhn; MOTTA, Roberta Fin. Representações midiáticas da internação compulsória de usuários de drogas. Temas em Psicologia, v. 22, n. 2, p. 433444, 2014. 


\section{Errata}

No artigo "A controvérsia em torno da internação involuntária de usuários de crack", com o número de DOI:10.1590/s0102-6992-201934020007, publicado no periódico Revista Sociedade e Estado, v. 34, n. 2: 513-538, na página 537:

Onde se lia:

MONTEIRO, Hildenete Fortes. A internação psiquiátrica compulsória: uma abordagem à luz dos direitos fundamentais. Dissertação (Mestrado em Direito) - Pontifícia Universidade Católica do Rio Grande do Sul, Porto Alegre, Rio Grande do Sul, 2015.

Leia-se:

MONTEIRO, Fábio de Holanda. A internação psiquiátrica compulsória: uma abordagem à luz dos direitos fundamentais. Dissertação (Mestrado em Direito) - Pontifícia Universidade Católica do Rio Grande do Sul, Porto Alegre, Rio Grande do Sul, 2015.

\section{(c) $($ ) 8 (9)}

